\title{
Correction to: Arachnoiditis as an outcome factor for microvascular decompression in classical trigeminal neuralgia
}

\author{
Edoardo Mazzucchi ${ }^{1} \cdot$ Andrei Brinzeu ${ }^{2,3,4} \cdot$ Marc Sindou $^{2,3}$
}

Published online: 20 November 2019

(C) Springer-Verlag GmbH Austria, part of Springer Nature 2019

Correction to: Acta Acta Neurochirurgica (2019) 161:1589-1598

https://doi.org/10.1007/s00701-019-03981-7

Correct figure 3 is shown below:

The online version of the original article can be found at https://doi.org/ 10.1007/s00701-019-03981-7

$\triangle$ Andrei Brinzeu

andrei.brinzeu@chu-lyon.fr

Catholic University of Sacred Heart, Rome, Italy

2 University de Lyon 1, Lyon, France

3 University of Medicine and Pharmacy Victor Babes Timisoara,

Timisoara, Romania

4 Service de Neurochirugie Fonctionelle, 59 Boulevard Pinel, 69003 Lyon, France 


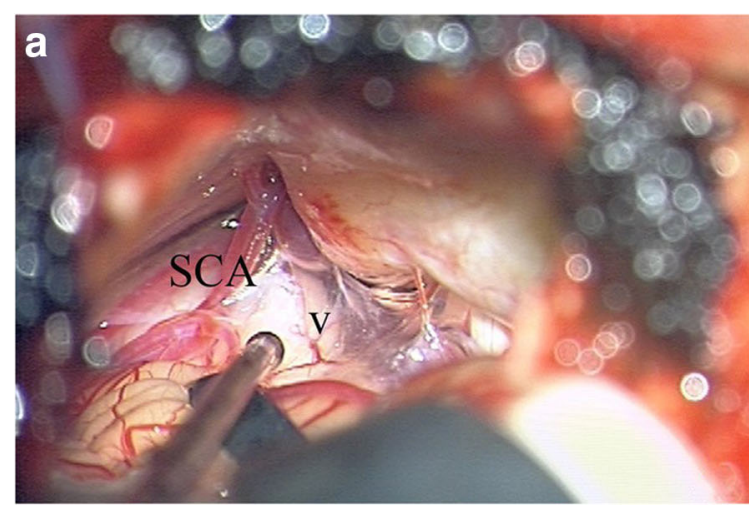

Fig. 3 a Normal arachnoid as seen in an rightside MVD surgery for TN. The arachnoid while present and touching the surrounding structures is not adhesive to them, is delicate and transparent and the structures are easily seen through it. b Intraoperative image illustrating a case of arachnoiditis. The arachnoid membranes are thick and they are

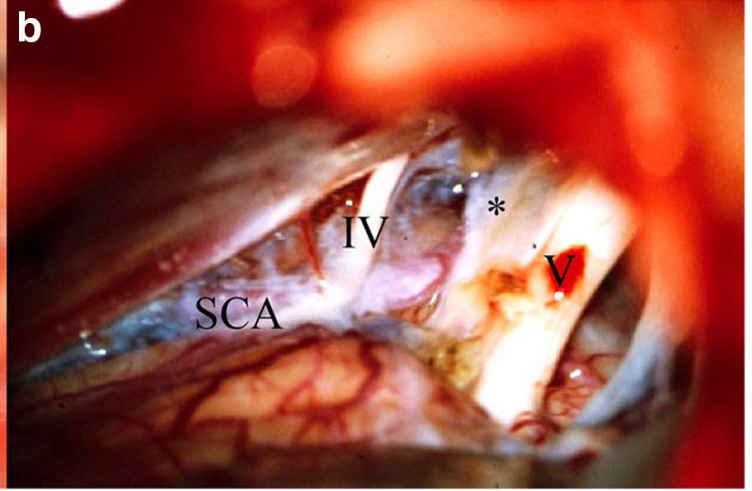

particularly adhesive to the trigeminal nerve and superior cerebellar artery. -Rightside MVD for TN. IV, trochlear nerve; V, trigeminal nerve; SCA, superior cerebellar artery; *thickened coalescing arachnoiditis between the SCA and the trigeminal nerve 